\title{
Assessment Of A State Commodity Marketing Program: A Case Study Approach Using 2003-2004 Texas Wine Marketing Assistance Program Evaluation
}

Roger D. Hanagriff, (E-mail: agr_rdh@shsu.edu), Sam Houston State University Stanley F. Kelley, (E-mail: sfkelley@shsu.edu), Sam Houston State University Marcy M. Beverly, (E-mail: mmbeverly@shsu.edu), Sam Houston State University Tim H. Murphy, (E-mail: tmurphy@tamu.edu), Texas A\&M University

\begin{abstract}
The Texas wine industry is a growing industry that impacts the states economy, offers gains in tourism and provides Texas jobs. This study shows the gains recognized from Texas Wineries during their participation (2004 fiscal year) in the Texas Wine Marketing Assistance Program (TWMAP) with comparisons made to the initial assessment for 2002 fiscal year. A questionnaire was created to assess the benefits to the wineries of the state of Texas which participated in the TWMAP program. When compared to the initial assessment (2002), participating wineries experienced an increase in all categories, for example, average sales, number of wineries participating in the program and visits to the wineries. A greater number of wineries participated in the programs, and a higher percentage believed that the TWMAP was beneficial to their business. Thirty percent more wineries reported sales increases, (67\% in 2003, 97\% in 2004) with average sales increase from $\$ 88,983$ in 2003 to $\$ 109,387$ in 2004 creating a total economic impact increase from $\$ 4.1$ million to $\$ 10.1$ million. The ROI increased from $930 \%$ to $1,400 \%$. The participants in the TWMAP attribute $35.4 \%$ of their sales increases directly to the TWMAP, amounting to \$3.57 million in economic benefit for the state, with programming costs of $\$ 250,000$. The TWMAP returned over $\$ 14$ for each $\$ 1$ of state funds invested, or 1,400\% return on state funding. This was an increase in the already impressive 930\% increase in returns reported in 2002. In light of these trends in this program, it is clear that the TWMAP is establishing a pattern of success and the existence of a marketing campaign has had a successful economic impact on the growth of the Texas wine industry.
\end{abstract}

\section{INTRODUCTION}

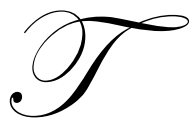

he Texas wine industry is the country's fifth-leading wine-producing state, and the number of wineries continues to grow. In the past two decades Texas wine production has surged, from 24,000 gallons in 1981 to a high of 1.26 million gallons in 1997. The Texas Wine marketing Assistance Program (TWMAP) was established in 2001 to support this growing industry by promoting Texas wines, and by educating the public about the Texas wine industry. This industry contributes over \$170 million in Total Economic Impact, and over \$3.5 million in direct excise and state tax revenues. The TWMAP offers public education programs about the wines produced in the state, the promotion of Texas wines and wineries, and the use of research to establish a wine industry marketing plan to increase the consumption of, and access to, Texas wines. 


\section{METHODOLOGY}

Within the realm of this research, a questionnaire was created to assess the benefits of the TWMAP to the wineries of the state of Texas. This survey included questions concerning the type of Texas Department of Agriculture (TDA) sponsored activities that the wineries have been involved in, types of TDA promotional materials wineries used, and how the program has affected the overall awareness of the Texas wine industry. To ascertain program effectiveness, participants were asked to quantify sales volume, winery visitations, and annual sales increases. Wineries were also asked to estimate the impact the TWMAP represents to their wine business as a percentage of their sales.

This effort addresses increases in sales reported by responding wineries since the implementation of the TWMAP in 2001. This data is not intended to measure the overall size of the Texas wine industry, but rather to focus on the progress of the industry since the implementation of the TWMAP. Results are intended to measure the effectiveness of TDA wine marketing efforts, provide information to improve these efforts, and increase future program results. This is the second evaluation (2004 fiscal year) of the TWMAP program, with the initial assessment measuring the effectiveness of the 2002 fiscal year. Comparisons to the 2002 report were completed to measure program growth and identify changes to improve program effectiveness.

\section{RESEARCH SAMPLE}

Of the 46 surveys mailed to participating wineries, 33 (72\%) were returned. To determine the size of involved firms, the wineries were asked to report their total annual sales. Most Texas wineries are relatively small, but some have grown to significant size in the national market. The average annual sales for the responding wineries were $\$ 824,190$. Forty-eight percent of the wineries (15 of the 33) reported sales of less than $\$ 500,000$. There were six wineries that reported sales of over a $\$ 1$ million, and two of these reported sales over $\$ 4$ million.

\section{ANALYSIS OF MARKETING ASSISTANCE}

A general assessment regarding the impact of the TDA marketing assistance program is that an overwhelming $97 \%$ of wineries felt the program has positively impacted their business in some way. This was up slightly from the 94\% reporting a positive impact in the 2002 survey. These recognized benefits included sales increases, increases in visitations to the winery, and the use of marketing activities and promotional materials developed by TDA. These benefits were realized by members who are actively participating in TDA supported marketing activities. The marketing programs and events also appear to be well publicized as $100 \%$ of the respondents indicated that they were familiar with the program.

Over $90 \%$ of the wineries participated in TDA sponsored Texas wine tastings and events, and have used TDA-produced Texas wine promotional materials. Other levels of participation in marketing activities are reported in Figure I. In 2004, 97\% of the wineries indicated that these activities had a positive impact on their sales volume. When examined with the $90 \%$ reporting a positive impact in 2002, it becomes clear that producers see these events as increasingly effective.

A particularly generic aspect of marketing assistance was the use of TDA promotional materials (Figure II). This includes various promotional items, retail signage, printed materials, tradeshow booths and displays. Over $50 \%$ of the wineries utilized all types of materials, but the use of these materials varies among the needs of each winery. The most utilized promotional materials are printed materials. Some $97 \%$ of the wineries responding made use of these general promotional materials that are relevant to all wine businesses. Compared to the 2002 report, fewer respondents reported using Promotional Items and Retail Signage, but more reported using Tradeshow Booths and Displays. 
A direct benefit from TDA wine marketing activities and promotional materials was an increase in the number of visits to Texas wineries. Increasing winery visitation is a potential direct opportunity to increase sales, and is one of the goals of TDA sponsored marketing activities. For the evaluation , 97\% of wineries reported an increase in on-site visits. This is a substantial increase from the 78\% reported in the 2002 year. As reported in Figure III, onsite visits to Texas wineries increased. These visits have the potential to increase brand recognition, sales revenue, and ultimately generate a positive economic impact.

\section{ECONOMIC IMPACT}

Changes in economic impacts of the TWMAP were also assessed using information provided by the wineries. The wineries reported their un-audited annual sales totals and their average annual sales increases since the launch of the program. This information was used to estimate sales increases experienced by the wineries during this program, economic impacts to Texas from these sales increases (using the IMPLAN Model), and value added impacts to Texas.

In this report, a large percentage (97\%) of the wineries indicated that they have seen an increase in sales since the launch of the TWMAP. The average sales increase per winery was $\$ 109,387$ and the use of inferential statistics creates a total estimated sales increase for all wineries of over $\$ 5.0$ million ( $\$ 109,387 * 46$ wineries). Sales increases create secondary impacts to the economy and bring additional revenues to Texas; therefore they must be considered to correctly measure the impacts of an industry.

Economic impacts were derived from these sales figures using the IMPLAN model. In addition to economic impacts, the IMPLAN model estimates value added economic benefits. Value added figures recognize the additional value of employee wages and benefits, owner's compensation, dividends, capital outlays and business taxes paid. The average increase in economic impact per Texas winery derived from these sales increases was $\$ 199,236$, and the total projected economic impact for all Texas wineries reaches $\$ 9.16$ million $(\$ 199,236 * 46$ wineries). Value added impact for each winery was over $\$ 20,000$ and extrapolated to all 46 wineries was $\$ 922,813$ (\$20,061 * 46 wineries). Considering both the economic and value added impacts to Texas, it was determined that the Texas wine industry generated $\$ 10.1$ million (9.16M eco impacts $+.922 \mathrm{M}$ in value-added) in annual impact to the Texas economy while operating under the TWMAP.

The responding wineries recognized that TDA's wine marketing program (TWMAP) provided many opportunities to capture additional sales, but a conservative approach in program assessment requires that we recognize that their sales increases may also be attributed to their own marketing efforts, industry trends, and a host of other factors. To specifically target the recognized benefits of the TWMAP, respondents were asked to estimate the percentage of these increases in sales they would attribute directly to the TWMAP.

The respondents reported increases in sales of $35.4 \%$ was directly attributable to the TWMAP. Considering the total estimated economic benefit of \$10.1 million, \$3.57 million dollars in direct and value added economic impacts to the Texas economy can be directly attributed to the TWMAP ( $\$ 10.1$ million * 35.4\% $=\$ 3.57$ million).

Total impacts are illustrated in Figure IV, but a ratio of TDA funds utilized for the Texas wine program (TWMAP) provide a relative measure of program success. Annual funding for the TWMAP is $\$ 250,000$, and an economic impact of $\$ 3.57$ million is directly attributable to the program.

Considering the annual TDA funding of $\$ 250,000$ for the TWMAP, there is a $\$ 14.28$ impact directly to the Texas economy for each dollar invested in the program (3.57M / 250K). The percent Return on Investment (ROI) would be some $1,400 \%$ for program funds invested in the TWMAP. This is, by any measure, an outstanding return on investment. 


\section{RESULTS FROM EVENT PARTICIPATION}

Pearson correlations were performed to determine if there were relationships between TWMAP activities and measurable benefits to the wineries. These correlations determine if there are statistical relationships between TWMAP variables, such as participation in marketing activities and use of promotion materials, with program objectives such as increases in sales. While the number of respondents in this evaluation is small, the statistical procedure is able to control for the small data set. Correlations were reported only if they were significant (>95\%). This is a conservative approach to marketing program assessment.

A significant $(\mathrm{p}>.05)$ positive correlation $(\mathrm{r}=.453)$ was found between participation in TWMAP marketing activities and sales increases in dollars. This signifies the more activities wineries participated in, the greater the amount of their sales increases in dollars.

A significant $(\mathrm{p}>.01)$ positive correlation $(\mathrm{r}=.507)$ was found between participation in GO TEXAN events and sales increases in dollars. This identifies the wineries who increased participation in GO TEXAN events, experienced greater increases in sales.

A significant $(\mathrm{p}>.01)$ strong positive correlation $(\mathrm{r}=.793)$ was found between increased visits to the wineries and sales increases in dollars. This shows wineries experiencing increases in visits, also experienced greater sales increases in dollars. The Coefficient of Determination $\left(\mathrm{R}^{2}\right)$ for this relationship would be $62.9 \%$. That would identify $62.9 \%$ of the difference in sales increases in dollars can be explained by the differences in percentage increases in visits to the wineries. Another way to say it would be, more visits equals more sales, and since that is a goal of the TWMAP, it would suggest an appropriate program priority.

It is important to remember not all marketing efforts achieve statistically significant relationships with their objectives. We may believe efforts to increase visits to Texas wineries will increase sales at those wineries, but now we have statistical evidence this is a true statement.

While increasing visits to the winery was clearly important in increasing sales, so was participation in the TWMAP program. Wineries that reported participating in more TWMAP activities, participating in the GO TEXAN events, and using more TWMAP marketing materials experienced greater sales increases in dollars. This statistical relationship verifies the TWMAP did affect sales, economic impacts, and the creation of additional state tax revenues.

\section{CONCLUSIONS}

The Texas wine industry impacts the Texas economy by over $\$ 170$ million, offers gains in tourism that reach nearly \$24 million, and provides over 1,600 Texas jobs. The gains recognized from Texas wineries during participation in the TWMAP have reached outstanding levels. The annual sales increases of Texas wineries exceeded $\$ 5.0$ million, providing \$10.1 million in economic and value added impacts to the Texas economy. The initial report, issued in 2002, established that the TWMAP was an economic success. This second report indicates that the Texas Wine industry is growing dramatically and the TWMAP has been a success in assisting in this growth.

When compared to the first report (2002), there were increases in every category. Greater numbers of wineries participated in the programs, and a higher percentage believed that the TWMAP was beneficial to their business. Thirty percent more wineries reported sales increases, (67\% in 2003, 97\% in 2004). The average sales increase went from $\$ 88,983$ in 2003 to $\$ 109,387$ in 2004. The total economic impact increased from $\$ 4.1$ million to $\$ 10.1$ million. The ROI increased from $930 \%$ to 1,400\%. In light of these trends in this new program, it is becoming clear that the TWMAP is establishing a pattern of success.

The participants in the TWMAP attribute $35.4 \%$ of their sales increases directly to the TWMAP, amounting to $\$ 3.57$ million in economic benefit for the state, while costing program funds of $\$ 250,000$. The TWMAP returned over $\$ 14$ for each $\$ 1$ of state funds invested, or $1,400 \%$ return on state funding. This was an increase in the already impressive 930\% increase in returns reported in 2002. 
Finally, significant and positive statistical relationships were found between Texas Department of Agriculture activities and promotional materials, and increases in sales for the participating Texas wineries. Continued funding of this program is clearly warranted.

These significant results in achievements for the Texas program offer opportunities for other state commodity marketing programs. It appears that a state marketing program can assist in changes private businesses sales, which creates additional state tax revenues and encourages overall economic growth. States considering such a program would be encourages to expanding marketing support efforts to include distribution of more promotional materials, exploring new opportunities to promote state products directly to consumers (example wine tastings) , encourage involvement with producers, and complete an annual assessment report to ensure the program continues to meet the needs of state producers.

Figure I. Participation in areas of TDA Wine Marketing activities

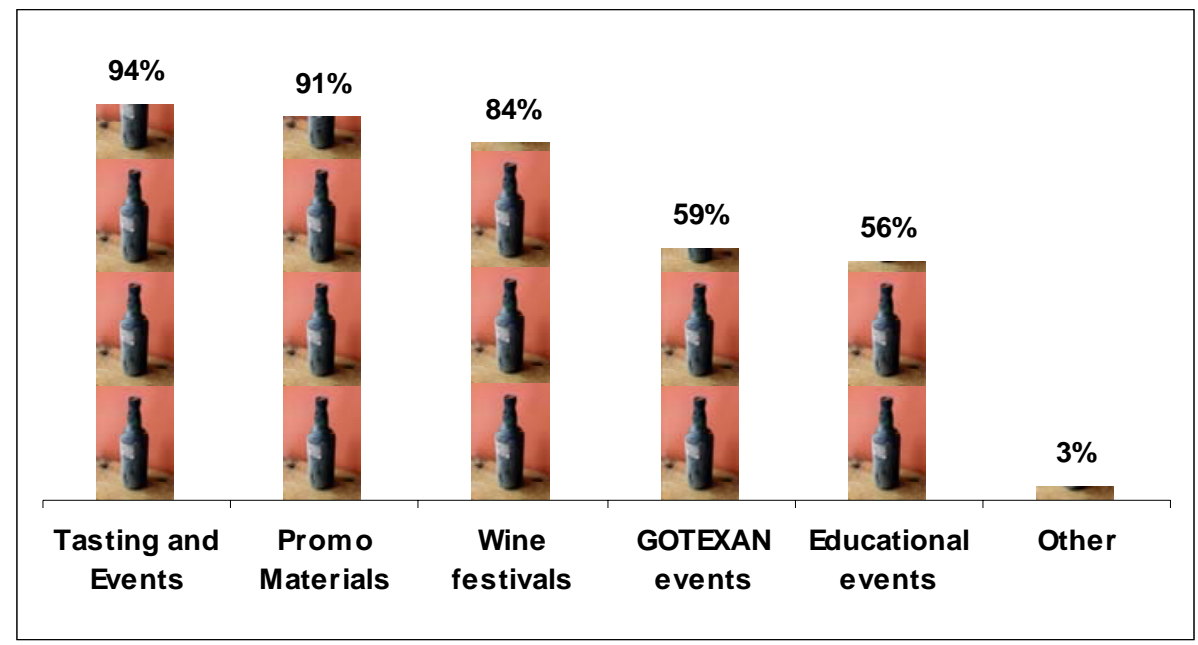

Figure II. Use of Promotional Materials

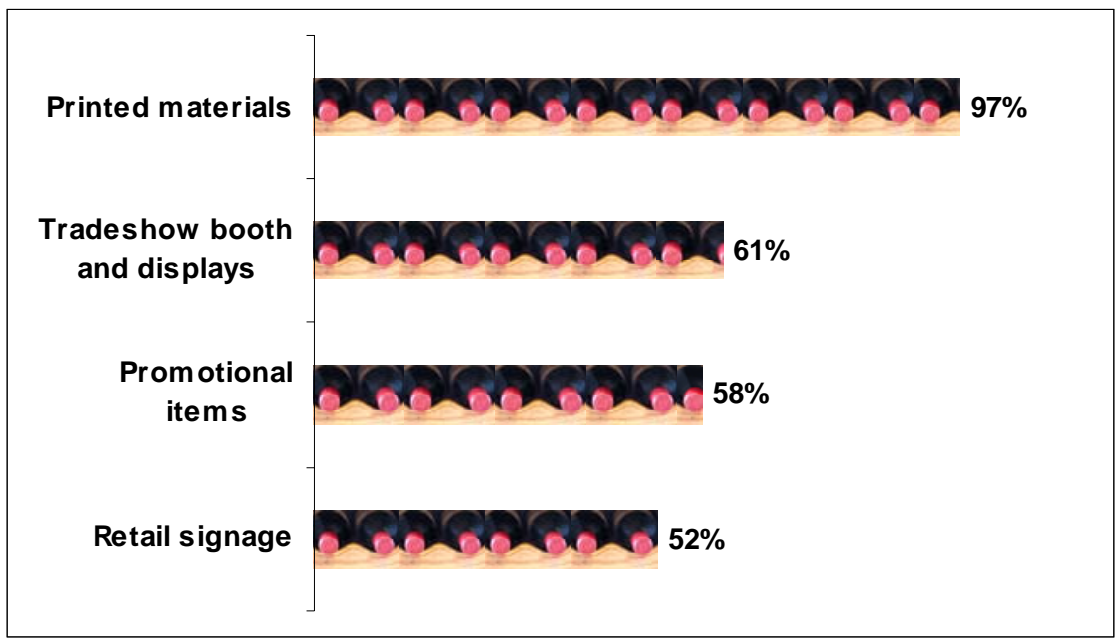


Figure III. Increased Visits to Texas Wineries

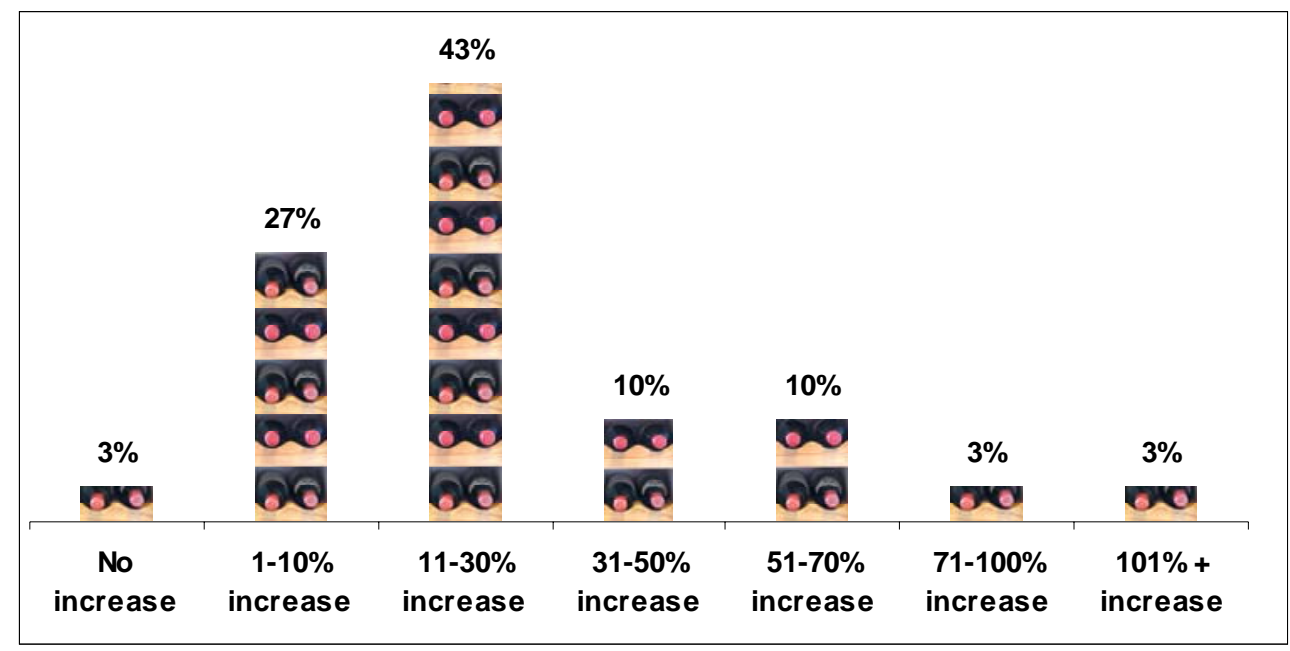

Figure IV. Annual TDA Wine Funding \& Economic Impacts from Texas Wineries

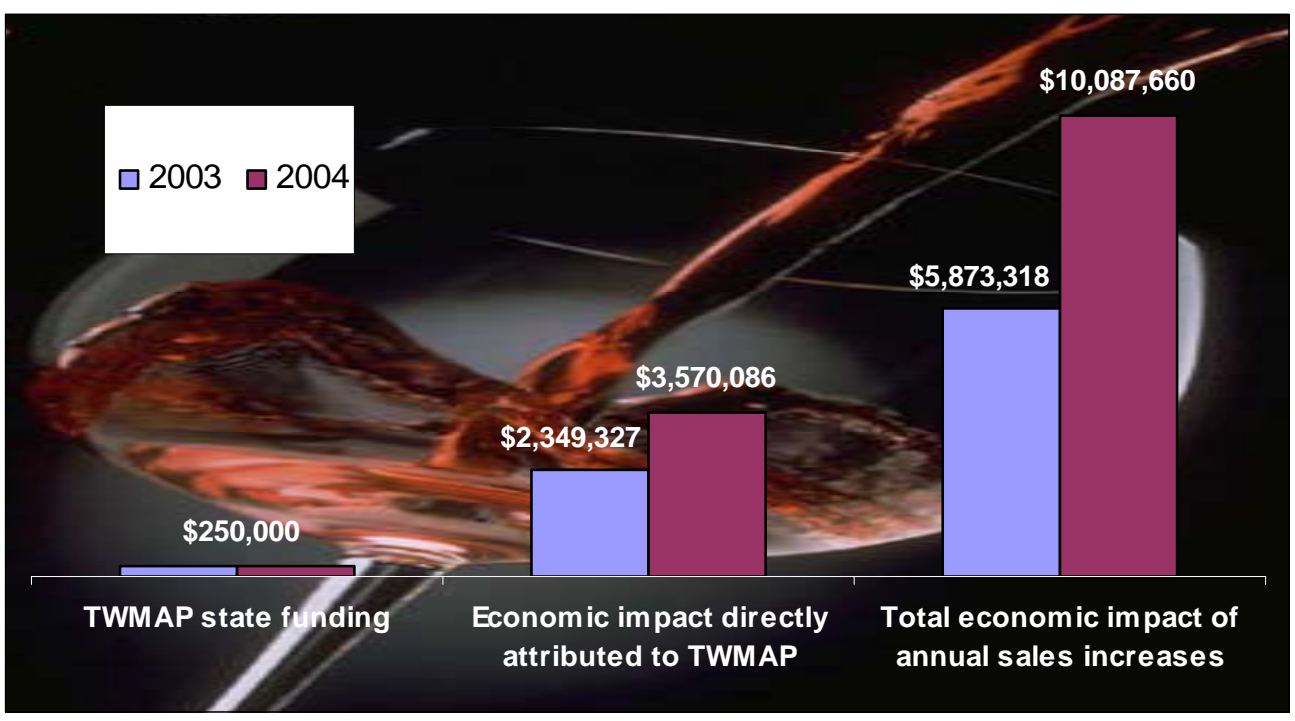

